\title{
LA VERDAD SOBRE EL ALEPH. CONTRAPUNTO HUMORÍSTICO ENTRE FONTANARROSA Y BORGES
}

\author{
CRISTIAN PALACIOS \\ Universidad de Buenos Aires - Conicet
}

De inmensa popularidad en Argentina y Latinoamérica la obra de Roberto Fontanarrosa ha sido escasamente estudiada por la crítica académica. En parte, quizás, debido a su éxito; pero mucho más probablemente por su carácter fundamentalmente humorístico. Una tardía reivindicación en los últimos años de su vida por ensayistas de la talla de Daniel Link, Juan Sasturain, Guillermo Saccomanno, Eduardo Romano o Sergio Olguín buscó ponderar la obra del escritor rosarino en su condición literaria como parte de la Gran Literatura Argentina. Esa nota no debe hacernos olvidar, sin embargo, que Fontanarrosa perteneció principalmente a otro campo. Ese campo es el humorismo y en nuestra tesis (Palacios 2014) hemos procurado demostrar por qué sí puede nombrárselo y estudiárselo de esa forma ${ }^{1}$. Por qué puede afirmarse del territorio de la risa que

\footnotetext{
${ }^{1}$ Al considerar la literatura o el humorismo como campos discursivos nos remitimos al uso de dicha noción en la obra de Dominique Maingueneau (2005, 2008, 2010) como un desarrollo teórico posterior y en el marco del Análisis del Discurso, del concepto de campo acuñado por Pierre Bourdieu (2002). Somos conscientes de que otros posibles abordajes arrojarían quizás resultados ligeramente diferentes. Así, las relaciones entre el humorismo y la literatura podrían ser estudiadas en el marco de la teoría de los polisistemas (Even-Zohar 1990 y 1999) como sistemas que se interrelacionan hacia el interior de una cultura en la que se inter-influyen mutuamente. Para este tipo de teorías la idea de temporalidad es clave, puesto que lo que hoy se encuentra en el centro del sistema, puede variar en cuanto varíen las reglas que han permitido su canonización. Con todo, las diferencias entre uno y otro punto de vista no nos parecen relevantes para la hipótesis que queremos demostrar aquí. En todo caso, ambas pueden enmarcarse dentro de lo que algunos
} 
conforma un campo discursivo, al igual que la literatura y el periodismo. Es decir, que los discursos elaborados en su interior no pueden nunca comprenderse como un conjunto de decisiones tomadas por un sujeto en la soledad de su estudio; sino como un complejo entramado de fuerzas en el que comienzan a pesar las regulaciones que, de manera más o menos inconsciente, ese sujeto se ve llevado a adoptar por su pertenencia a aquel. Al igual que en el campo literario, los humoristas no se forman en una institución específica (como los ingenieros o los químicos), sino que surgen en otros espacios, a partir de otros oficios, y en algún determinado momento se "profesionalizan" y pasan a ser reconocidos como tales por el resto de la sociedad. Al igual que en el campo literario, también, los profesionales de la risa reivindican su derecho a "hablar de todo" y los escándalos que cada tanto se desatan en los medios sobre los límites del humor forman sin duda parte de este proceso (Possenti 2010 y Palacios 2014).

En nuestra tesis hemos procurado demostrar además la excepcionalidad de la obra historietística y gráfica de Fontanarrosa tanto como su capacidad para realizar operaciones de producción de una extrema profundidad política en terrenos en los que por lo general se cree que solo la Literatura o el Arte (con mayúsculas) puede acceder. Nuestro propósito fue comprobar cómo desde el estricto territorio del humor, Fontanarrosa pudo decir cosas e intervenir en debates tradicionalmente reservados a otros dominios. Por ejemplo, la posibilidad de fundar a través de su personaje Inodoro Pereyra un "gauchesco urbano", en palabras del poeta Leónidas Lamborghini, realizando desde la historieta lo que este quería hacer desde la poesía (Lamborghini 2008 y 2003). Eso es porque el humor, según nuestro punto de vista, tanto como la ciencia, la filosofía o la literatura, es también una forma de considerar el mundo, distinta de aquellas.

Pensar el humorismo como un campo discursivo implica pensar también el problema de los niveles de legitimidad y transferencias de los distintos campos entre sí. Una obra que podría tildarse de "periodística" puede reclamar ser leída como "literaria" (A sangre fría de Truman Capote) o, a la inversa, la inclusión de una obra en el espacio de lo literario, puede también silenciar alguna de sus cualidades periodísticas y, por lo tanto, políticas (Operación masacre de Rodolfo Walsh, ver al respecto García 2012 y Aguilar 2000). En el caso que nos ocupa, según hemos mencionado, pudo suceder que diversos representantes del campo literario lamentaran que las novelas y relatos de Fontanarrosa no hubieran ingresado en el terreno de la literatura argentina, al que creían que su obra pertenecía por derecho propio. Está claro que ser un escritor es mucho más prestigioso que ser un humorista y la reivindicación de Fontanarrosa como literato estaba fundamentalmente dirigida a hacerle justicia.

teóricos entienden como teorías sistémicas (Lambert 2006), en tanto y en cuanto consideran a la literatura como un sistema en proceso y, en consecuencia, perpetuamente cambiante. Lo mismo puede decirse del humorismo, aunque aquí los cambios demoran más tiempo, dado que no son percibidos por sus agentes, que rara vez reflexionan sobre las condiciones hacia el interior de su propio sistema, a diferencia de lo que sucede con la literatura. Para todo ello ver el capítulo 1.3 de Palacios (2014). 
En mi caso creo que esta estrategia es completamente errónea. Me parece que, al contrario, la cuestión reside en la posibilidad o imposibilidad de la crítica en reconocer operaciones de producción en el campo del humorismo y de las culturas populares, por lo menos tan complejas y profundas como las que se encuentran en el terreno de la literatura ${ }^{2}$. Incluso el mismo Fontanarrosa, en muchas de sus entrevistas, parecía considerarlo de este modo: "De mí se dirá posiblemente que soy un escritor cómico, a lo sumo. No me interesa demasiado la definición que se haga de mí. No aspiro al Nobel de Literatura. Yo me doy por muy bien pagado cuando alguien se me acerca y me dice: 'Me cagué de risa con tu libro'" (Braceli 1992). No hace faltar citar a Ricardo Piglia para recordarnos que no existen escritores sin teoría y que, por otra parte, la ingenuidad y el antiintelectualismo forman parte de una teoría bastante compleja y sofisticada que ha servido -según sus palabras- "para arruinar a muchos escritores" (Piglia 1986: 10). La tradición además señala que no hay que creerle mucho a los escritores (y mucho menos a los humoristas). La tradición del ensayo literario diría que más bien todo lo contrario. Que Fontanarrosa nos asegure, una y otra vez, su vocación anti-intelectual, no significa que su obra sea efectivamente ingenua y antiintelectual. La apuesta de este trabajo consistiría justamente en invertir un poco el sentido con el que se suelen realizar esas declaraciones. Todas ellas parecen dar por sentado que "hacer reír" y "contar historias" no tiene nada que ver con la literatura. Nosotros creemos que, al contrario, "contar historias" y "hacer reír" y sobre todo "hacer reír contando historias" son operaciones muy complejas en las que Fontanarrosa se desempeñaba particularmente bien. Y son operaciones que están en la raíz misma de la literatura (incluso de esa que gana premios Nobel).

Para demostrarlo, será necesario circunscribirnos al terreno de la obra. Será allí donde encontraremos nuestros mayores fundamentos para no creerle a Fontanarrosa en absoluto. La cuestión, de hecho, va a aparecer formulada de forma bastante sorprendente en su historieta más popular, a través de un encuentro entre Inodoro Pereyra y el escritor más emblemático de aquella literatura y de la cultura llamada alta.

El episodio en cuestión se titula "La Pampa de los senderos que se bifurcan" y fue publicado en el número 38 de la revista Hortensia en julio de 1973. Será la primera de tres apariciones explícitas de la figura y la obra de Borges en la obra de Fontanarrosa. Digo "explícitas" porque la hipótesis que me gustaría sostener aquí es que la influencia de la figura de Borges en la de Fontanarrosa es un poco más que meramente superficial. Esta influencia se traduce para mí en una operación a la que podemos aludir con el nombre de "gesto". Fontanarrosa, según este punto de vista, traduce el gesto que Borges había adoptado, en el interior de la literatura, para con la gran literatura europea, en su obra tempra-

\footnotetext{
2 Sobre el gesto "elitista" en los análisis sobre la cultura de masas puede consultarse Swingewood (1977), quien realiza una crítica particular sobre el punto de vista de Adorno y Horkheimer, para quienes la cultura de masas era fundamentalmente una "pseudocultura" (Adorno y Horkheimer 1994). Véase también Huyssen ([1986] 2006) y Muñoz (1995 y 2000). Para el caso particular que aquí mencionamos puede consultarse Schvartzman (2013: 77-84 y 449-450) y también Jitrik (1971: 23-44).
} 
na ${ }^{3}$. Ello más allá de las interferencias textuales que aquí señalaremos; junto con algunas otras de las que no nos ocupamos ${ }^{4}$.

Nuestro estudio constituye, por lo tanto, un capítulo de la todavía poco estudiada apropiación de la obra de Borges por parte de las "culturas populares" o de los lenguajes que por una razón u otra se adscriben al tipo de producciones que circulan con esa etiqueta ${ }^{5}$. Lo contrario, la apropiación por parte de Borges de muchos de los elementos de dichas culturas, ha sido mucho más estudiado y analizado al punto que podría decirse que constituye toda una rama de los estudios borgeanos ${ }^{6}$. Y esta es una consecuencia más del modo un poco "obtuso" (por decirlo de alguna manera) en el que todavía se jerarquizan los lenguajes.

El mismo Borges, en sus comienzos, parece adscribirse a esta perspectiva. Cuando, por ejemplo, en "El escritor argentino y la tradición" señala que "los poetas gauchescos cultivan un lenguaje deliberadamente popular, que lo poetas populares no ensayan" lo hace para aseverar después que las incorrecciones en las que recaen los poetas populares son directamente, según sus palabras, "producto de la ignorancia". Y sigue diciendo: "He podido comprobar lo mismo oyendo a payadores de las orillas; estos rehúyen el versificar en orillero o lunfardo y tratan de expresarse con corrección. Desde luego fracasan, pero su propósito es hacer de la poesía algo alto; algo distinguido, podríamos decir con sonrisa" (Borges 1989: 268-269). El problema, según lo señala Schvartzman, está "en el plural indiscriminado e ineluctable del 'fracasan', como una fatalidad de las orillas; en el 'desde luego' de un escritor que se caracterizó por los 'acasos'; y en la feroz condescendencia de la sonrisa final" (Schvartzman 2013: 83). Nos encontramos

3 Citar la demasiado extensa bibliografía al respecto requeriría de un dispositivo como el de "La Biblioteca de Babel". Un buen compendio de artículos sobre el tema puede encontrarse, sin embargo, en el número 12 de la revista Variaciones Borges, con un dossier dedicado a "Borges y el Humor", en el que no pocos de los artículos se detienen sobre este punto (Almeida y Parodi 2001). Del mismo modo pueden consultarse los artículos de Turbio (2006) y Martín (2004).

${ }^{4}$ Así, por ejemplo, hemos podido intuir un eco del cuento "Tlön, Uqbar, Orbis Tertius" en el título y en los procedimientos de la historieta "Pabis, Gurus, Laxos \& Praxis" (publicada en Satiricón n. ${ }^{\circ}$ 23, diciembre de 1975). De esta y de otras intertextualidades nos hemos ocupado en Palacios (2014), en particular en el capítulo 3.4, donde analizamos, a su vez, las reformulaciones que el propio Fontanarrosa ha realizado sobre textos de la literatura universal (en el que se incluyen los del propio Borges).

${ }^{5}$ En el artículo "Borges al cuadrado (o de cómo un grupo de superhéroes impidió que el mundo se convirtiera en Tlön)" (Adur Nobile 2012), se señalan diversas transposiciones de la obra de Borges al universo de las culturas masivas, incluyendo las numerosas adaptaciones de sus obras al cine (Cozarinsky 1981 y Cédola 1999); su presencia en algunas series televisivas (la miniserie televisiva Por el nombre de Dios, producida por Pol-Ka en 1999; el capítulo "Lisa, the iconoclast" de la serie animada The Simpsons); sus reiteradas apariciones en la historieta [el Perramus (1984) de Juan Sasturain y Alberto Breccia; la historieta "¡José María SUPERPLON Vs. CULTURIN!" publicada en Humor registrado, n. 12, abril de 1979; o la más sorprendente transposición estudiada por Adur Nobile del cuento "Tlön, Uqbar, Orbis Tertius" al comic de superhéroes Doom Patrol]. Yo agrego un universo más a ser tenido en cuenta: el teatro. Por ejemplo Cita a ciegas de Mario Diament Borges de Rodrigo García y la mucho menos interesante Borges y Perón de Enrique Estrázulas.

${ }^{6}$ Se han realizado diversos estudios sobre la relación de la obra de Borges con el género policial (por ejemplo Fernández Vega 1996, Parodi 2006 y Louis 1997), el cine (Cozarinsky 1981, Speranza 2006 y Oubiña 2007) y la ciencia ficción (Abraham 2005). Debo la noticia de gran parte de esta bibliografía al ya citado artículo de Lucas Adur Nobile (2012). 
entonces con el prejuicio que ya hemos señalado al comienzo: la presuposición de que los autores de la cultura "alta" hacen lo que hacen a sabiendas y con total dominio de la situación, mientras que a los autores de la contraparte no puede atribuírseles ninguna intencionalidad en los logros que podrían ser celebrados incluso por los autores de la cultura "alta". Borges, entre otros ${ }^{7}$.

La cita no tiene pérdida porque además sucede que la historieta en la que se produce el encuentro es justamente Inodoro Pereyra, la tira más famosa de Fontanarrosa que, creo yo, merece un lugar muy especial en la serie de obras que integran el género gauchesco. He intentado demostrar en varios capítulos de mi tesis que más que pensar a esta historieta como una parodia de aquel género se le hace mucho más justicia pensándola como una continuación. Según mi punto de vista, Inodoro Pereyra no parodia a la gauchesca, ese tramo específico de la literatura argentina cuyo final la crítica coincide en ubicar hacia mediados de la década de los setenta del siglo xıx (doble final, con la publicación de La vuelta, por una parte, y del Fausto, por la otra). La operación constitutiva de la primera etapa de Inodoro (de 1972 a 1976) es la parodia de algo que yo llamaría "lo gauchesco", un transgénero que para ese entonces ya ha transitado por el radioteatro, el cine, la historieta (seria y humorística), el folklore y la novela de folletín ${ }^{8}$. Es decir, no hay parodia de aquel género literario, sino de lo que vino después. Y lo que vino después recuperó muy poco de la operación original de aquella gauchesca. En Inodoro, sin embargo, se da un caso distinto. Por una serie de operaciones que no tienen nada de ingenuas, Fontanarrosa recupera ese gesto, pero poniendo en el lugar de ese "otro" no al gaucho, puesto que hacia los años setenta del siglo pasado el proletariado rural tenía muy poco que ver con ese gaucho encarnado por Inodoro, sino a las clases populares urbanas ${ }^{9}$.

Lo más interesante es que este proceso no se da en un episodio particular, sino a todo lo largo de los primeros años de publicación de la tira, aproximadamente hasta 1976. Después, Inodoro va a mutar y transformarse. Primero con su pasaje a la revista Siete Días Ilustrados y luego, a partir de 1978, al diario Clarín. Pero en los primeros años y en los primeros capítulos, se realizan una serie de estrategias discursivas que apuntan en la dirección que estoy señalando. Una de ellas es el motivo de los encuentros. Inodoro, el gaucho, se encuentra en su cuarto episodio con Antonio das Mortes, el matador de cangaçeiros de la pelí-

\footnotetext{
7 Puesto que nosotros por lo general estudiamos las obras tal y como nos han sido legadas, se podría decir que la cuestión de la intencionalidad es un poco estéril y así lo sería si no fuera porque aún la crítica literaria que le niega a esta intencionalidad un papel en el sistema, echa mano de ella -como lo hace aquí Borges- para legitimar y defender ciertas lecturas de ciertos lenguajes por sobre otros.

8 ... (tipos de textos que comparten en común rasgos retóricos, temáticos y enunciativos) que no se limita a un lenguaje artístico determinado, sino que se expande a través de muchos de ellos (cine, radio, televisión, música, etc.). Ver al respecto Steimberg (2013).

9 Se da entonces ese fenómeno que hemos mencionado un poco antes, llamado por el poeta Leónidas Lamborghini, como "gauchesco urbano" (dudo que Leónidas Lamborghini y Fontanarrosa se hayan encontrado alguna vez, aunque podría ser posible, recordemos que su hermano Osvaldo, había sido el temprano guionista de la serie "¡Marc!"). Y creo que Inodoro Pereyra encaja perfectamente en esa definición.
} 
cula de Glauber Rocha; película cuyo tenor político no era desconocido, ni ahora ni entonces. Este encuentro propone, de forma un tanto encubierta, una cierta analogía entre gauchos argentinos y cangaçeiros brasileros. En el número anterior, había medido fuerzas, por así decirlo, con una tal Soledad, la hija del patrón, para descubrir, hacia el final del episodio que "no era torcaza pa este gavilán" mientras la voz narradora comentaba que "Hacia el este, empezaba a alborear la conciencia de clase". En el número 36 de Hortensia, Inodoro se encuentra con un tal Yon Darwin, para medir fuerzas nuevamente, esta vez con un científico inglés. En el número 37 es visitado por dos campesinos de la revolución mexicana. Se trata de una nueva analogía. Cangaçeiros brasileros, campesinos mexicanos y gauchos argentinos son puestos entonces, en una relación de igualdad. En el episodio siguiente, se produce el encuentro con Borges.

Este encuentro, como todos los demás, toma la forma de un intento de comunicación frustrada entre el escritor y el gaucho, a través de una serie de equívocos que se traducen también en un contrapunto: [Inodoro] "usté parece hombre léido" [Borges] "'Léido' no. 'Leído' se dice. Palabra grave" [Inodoro, tras una pausa] "'Facón' es una palabra grave". Como se ve, lo que se subraya es la figura del escritor y no su obra. Esto se pone en evidencia, principalmente, en la siguiente réplica de Borges: "el sol sobre tu frente alumbre tu lenguaje camarada"; que es nada más y nada menos que una cita con alteración de la "Marcha de la libertad" compuesta por Manuel Gómez Carrillo y Manuel Rodríguez Ocampo en pos de la llamada Revolución Libertadora ("el sol sobre tu frente / alumbre tu coraje camarada"). Se trata, por lo tanto, de un comentario sutil, sobre el costado anti-peronista del Borges público ${ }^{10}$.

Al final, Borges acaba por concluir "Es inútil, somos un símbolo: Civilización y Barbarie". En esta línea, quedaría perfectamente claro a quién le corresponde cada denominación, sin más comentarios. Pero no. En primer lugar, porque la historieta no termina aquí. Inodoro, de hecho, rehúsa hacer lo que dice Mendieta: "lárguelo sólo a este viejo. Nos desprecea". En su lugar, replica con una estrofa alterada de la canción "El corralero" de Sergio Mauvalle: "[Inodoro] déjelo nomás pasar, Mendieta, / yévese de mi consejo / que yo lo voy a enterrar / cuando se muera de viejo" ("déjelo nomás pasar / no rechace mi consejo / que yo lo voy a enterrar / cuando se muera de viejo"). Yo he insistido mucho, cada vez que he tenido oportunidad, en señalar las diferencias en toda obra humorística entre aquellos chistes que se proponen con el solo fin de disparatar (a la manera de "temo que me atropelle el malón de las seis") y aquellos cuya gracia reside en la comprensión de un sentido oculto, de una cláusula ingeniosa, de un pensamiento serio. Creo que esta última cita es el segundo caso. No se trata de una réplica meramente ridícula, sino de una ironía que nos permite leer aquí la posibilidad de una continuidad (de una apropiación) de la obra de Borges por parte de Fontanarrosa: Inodoro no lo suelta, sigue junto a él, cruzando la pampa, guiándolo en su ceguera a través del territorio vacío y horizontal de la historieta.

\footnotetext{
${ }^{10}$ Sobre el anti-peronismo y, en general, sobre las polémicas en torno a la figura pública de Borges, consultar el fantástico libro de Martín Lafforgue, Antiborges (Lafforgue 1999), una compilación de críticas, en su mayoría negativas, sobre la obra y el personaje.
} 
Este argumento puede apoyarse, también, en una segunda observación sobre el modo en que aparece representado Borges en esa página. Debe admitirse que es por lo menos singular. A excepción de los ojos desviados y del famoso bastón, no encontramos ninguno de los rasgos usuales que por lo general acompañan los retratos del escritor. Borges está encapuchado, escondido, enmascarado. Sabemos desde el comienzo que es él, sobre todo por el título (este título, sin embargo, no está en el original de Hortensia). Pero este Borges se parece más a El Monje, el oscuro personaje de La Balada del Mar Salado, de Hugo Pratt, que al propio Borges. De hecho, se parece demasiado a El Monje. Y como es bien conocida la influencia que Pratt tuvo en la temprana obra de Fontanarrosa, no se trata de un símil demasiado alocado. Si le creemos a Fontanarrosa, fue en Hortensia donde por fin se lanzó a la historieta "copiando sin asco a Pratt" según sus propias palabras. Pero ¿qué tendría que hacer aquí El Monje en medio de La Pampa, caracterizando a un Borges que se hace llamar Georgie?

Dejaré esta pregunta para el final, si se me permite, para pasar a la segunda aparición explícita de Borges en la obra de Fontanarrosa, esta vez ya no en alusión a su perfil público (al mito Borges) sino a su obra. Se trata de la transposición paródica del cuento "Hombre de la esquina rosada" publicada en el número 19 de la revista Satiricón en junio de 1974, casi un año más tarde, como parte de una serie de parodias sobre películas, clásicos de la literatura, clásicos de la literatura argentina y series de televisión. Como primera medida, además del título (que reemplaza la "esquina rosada" del cuento por la "casa rosada" obvia alusión al edificio presidencial de gobierno), tenemos una sustitución del nombre de Francisco Paredes por el de Imprudencio Navarro, una deformación burlesca del narrador poético del tango "El cuarteador" de Homero Manzi ("Yo soy Prudencio Navarro / el cuarteador de Barracas"). Es decir, que se le da al cuento una vuelta más de tuerca: allí donde Borges había intentado reproducir una temática y una manera de hablar de las orillas, Fontanarrosa vuelve a orientar la historieta hacia el tango, la mirada propia de las culturas populares sobre esas orillas. Un segundo cambio paródico reemplaza el apelativo de "Corralero" de Francisco Real por el de "Corralón" corrigiendo irrisoriamente al original ("le batían el Corralón no el Corralero como bolacean algunos. El Corralón porque había sido capo de la taquería y cada vez que se piraba un sopre, gritaba: ¡corralón...! ¡corralón!”).

La historieta construye la escena apelando a close-ups y a viñetas mudas. Los cuerpos se deslizan sobre la pista, siguiendo la música con ojos cerrados. Con ojos cerrados también la orquesta ataca lo que ha de ser seguramente un tango. La entrada del personaje es indicada por el sonido de la puerta ("Slam") y el primer plano de una pareja que mira asustada. El Corralón de Fontanarrosa se parece al Corralero de Borges ("un tipo alto, fornido, trajeado enteramente de negro, y una chalina de un color como bayo, echada sobre el hombro. La cara recuerdo que era aindiada, esquinada"). Luego de estas viñetas donde no hay chiste, tenemos un segundo desplazamiento hacia la serie política (el primero es el nombre: "Hombre la casa rosada" por "Hombre de la esquina rosada"): "Busco a Rosendo Juárez. Le dicen el Cuarteador y me ando maliciando que es de la Cuarta Internacional" ("El Cuarteador" es en realidad, en el tango de Homero Manzi, 
Prudencio Navarro). Imprudencio Navarro dice aquí haber sabido ser comisario "por Clínicas y La Bomba" y que le han pasado el "santo de que andas rechupado por los estaños, y un tipo que anda rechupado no acata la verticalidá".

Como se ve, de modo sutil, se introduce un tercer desplazamiento hacia lo político que juega con las dos lecturas posibles de aquella frase. "Acatar la verticalidad" es ante todo una manera graciosa de decir que al borracho le cuesta mantenerse en pie. Pero además, dicha verticalidad, puede entenderse en términos de "verticalidad política". Y no es extraño, dado que se trata de un ex-comisario que anda a la búsqueda de un comunista.

Imprudencio Navarro les recuerda a todos "antes de elegir a alguien consulten la comisaría más próxima" (estamos, hay que recordarlo, en junio de 1974) y se le aproxima a la Lujanera: "¿Por qué te dicen la Lujanera? Porque le hago promesas a la virgen de Lujan". El Corralero contesta entonces con una frase de Perón (nueva incursión en la política): "Acordate que mejor que prometer es realizar" (que aunque en este contexto tiene una obvia connotación sexual, no deja, sin embargo, de ser una frase de Perón) y agrega: "Lujanera... Son las 11 pm. Rajemos pa la zanja" y es esta vez la Lujanera quien dice: "Ya no sé si PM es pos meridiano, post mortem, policía militar o patria metalúrgica". Lo que sigue se parece al cuento. Rosendo Juárez se "arruga" y Borges, el narrador (le cubre el cuello un pañuelo con las iniciales J. L. B.) entra en escena ("¡Se arrugó Rosendo carajo!") para hacer justicia. El Corralero se va con la Lujanera (cita explícita) "Abran cancha que me la llevo dormida" (en el cuento: "¡Vayan abriendo cancha, señores, que la llevo dormida!"). Y Borges se retira. Casi de inmediato se escuchan los gritos: "entrá guacha, arrastrada..! entrá te digo" [en el cuento: "Ajuera oímos una mujer que lloraba y después la voz que ya conocíamos [...] diciéndole: —Entrá, m'hija —y luego otro llanto. Luego la voz como si empezara a desesperarse. —iAbrí te digo, abrí guacha arrastrada, abrí, perra!"].

La muerte de Imprudencio Navarro se parece un tanto a la muerte del jubilado Polsky en la versión de El Eternauta de Alberto Breccia: una sucesión de viñetas mudas que se alejan mientras Polsky sale y va cayendo, poco a poco, muerto. Aquí el personaje entra y se acerca, pero también cae muerto poco a poco, al igual que en aquella. El final, sin embargo, tuerce las cosas otro tanto. Es Borges quien al llegar al bulín, como en el cuento, mira al cuchillo y comprueba que no tiene ni rastro de sangre. Sin embargo, luego, explica: "No me cabía que Rosendo Juárez, el Cuarteador fuera de la Cuarta Internacional. Lástima que en la oscuridá me confundí y achuré al Imprudencio Navarro" y concluye "es desde esa noche que uso lentes".

Finalmente, tenemos una tercera aparición explícita de Borges en la obra de Fontanarrosa; pero esta vez en el territorio que les llegó a ser común a ambos: el de la literatura. En este último caso confluyen las dos dimensiones del símbolo Borges. Además, cuando se publica, Borges ya está muerto. El dato carecería de importancia si no fuera porque este hecho se menciona en uno de los momentos más divertidos del relato.

Incluido en el último libro de Fontanarrosa publicado en vida, "El especialista o la verdad sobre 'El Aleph'" relata el arribo a la Argentina de Yoshio 
Kamatari, un crítico japonés especializado en la obra de Borges. Este lingüista, semiólogo y "vocabularista" ("es experto en vocabulario. Acá se ha interesado vivamente por la palabra 'serrucho'") se presenta frente al narrador, paradójicamente, como indescifrable: "Es difícil calcularle la edad" -dice el narrador"fenómeno que suele suceder con los orientales [...] puede inferirse que debe rondar por los setenta años. No obstante, como muchos japoneses, luce un pelo cano, corto, denso y tupido como el de una nutria" y a continuación agrega: "Kamatari es impenetrable. No pueden detectarse en él atisbos de sonrisa o de humor". El especialista parece ser, él mismo, una heterotopía viva (como aquella de la Enciclopedia China de "El idioma analítico de John Wilkins"), que provoca en Arturo, el narrador, una "particular incomodidad", "la molesta sensación de que a cada rato me estaba agarrando para la joda, si me disculpan el término" (Fontanarrosa 2005: 165).

Este oriental amigo de Yukio Mishima que no sabe que Borges ha muerto y que aprende el castellano en un sólo día ("Es notable la velocidad con que aprende las lenguas romances -dice Kamatari- la persona que ha estudiado latín. -¿Usted aprendió latín? -No. Por eso demoré tanto en aprender el castellano") sostiene la inquietante teoría de que Borges se drogaba. Frente a la revelación, el narrador se muestra francamente preocupado:

Kamatari me escudriñaba con sus ojos entrecerrados, reducidos entonces a dos rayitas. Serio.

-Vea - proseguí-, yo no podría arriesgar que Borges sea un ídolo popular como Gardel, o como Fangio, uno de esos ídolos amados por el pueblo. Es más, le diría que Borges siempre ha sido cuestionado por las clases más humildes, con justicia o no, por reaccionario, o antiperonista, por presuntamente oligarca, por no compartir la afición general por el futbol...

-No he leído nada de Fangio [Interrumpe el japonés]

-...pero toda esa gente que lo denosta, incluso los críticos de izquierda, se pondrían de su lado, del lado de Borges, si aparece un extranjero atacándolo, calificándolo de adicto a las drogas. (Fontanarrosa 2005: 166)

La teoría de Kamatari parece sostenerse sobre la idea de que "solo una persona bajo el efecto de alucinógenos puede describir algo como el Aleph". Frente a lo cual Arturo insiste una y otra vez: "Es ficción, Yoshio".

"El especialista" culmina entonces la línea de lectura que en la obra de Fontanarrosa empieza con aquella primera irrupción de un Borges encapuchado en las páginas de Inodoro Pereyra y que se perpetúa en la parodia de la revista Satiricón un año más tarde. En la primera el acento estaba puesto sobre la figura pública del escritor y su lugar como representante paradigmático de la cultura letrada. En la segunda aparece retratada -parodiada- una de las dimensiones de su obra: el Borges de las orillas, del tango, del suburbio. En esta tercera inclusión -explícita- del cuento, se conjugan ambas líneas. Porque lo que el final reserva para la sorpresa del narrador y de los lectores es la más audaz de las teorías de Kamatari: la de que el Aleph era en realidad un televisor diminuto: "Mis investigaciones en la calle Garay [...] y, fundamentalmente, lo que me contó el sobrino 
nieto de Beatriz Viterbo, así lo confirman: lo que vio Borges era un televisor" (Fontanarrosa 2005: 169). La estrategia propia del humorismo de hacer atravesar un discurso extra-cotidiano por los patrones de lo cotidiano "bajando a tierra", por decirlo de alguna manera, aquello que el discurso precedente ponía sobre las nubes; se encuentra mediada aquí por un hecho todavía más significativo: el de que la más extraordinaria fantasía borgiana resulte disuelta en el símbolo paradigmático de la cultura masiva del siglo $x x$.

La hipótesis que vengo a sostener aquí, se encuentra, creo yo, confirmada por esta operación final del humorismo en este relato. A lo largo de su obra, Fontanarrosa retoma, reformula y transforma la obra de Borges con un sentido político muy preciso: el de invertir el gesto de la gauchesca decimonónica, que hacía uso de la "voz" de la culturas subalternas, desde el campo de la cultura letrada. Aquí, partiendo de la apropiación de la obra de Borges, se trata de hacer uso de la cultura letrada desde un tipo de lenguaje tradicionalmente adscripto a la cultura de masas, para acabar, finalmente, disolviendo los límites y las diferencias entre una y otra. Dado que hacia el final del relato nunca llegaremos a saber si Kamatari hablaba o no hablaba en serio.

De allí que el primer episodio de Inodoro Pereyra (en realidad, el segundo en ser publicado en Hortensia, pero, a partir de entonces, el que aparece primero en todas las antologías) "Cuando se dice adiós" (publicado sin título en Hortensia n. ${ }^{\circ}$ 25, diciembre de 1972) retome, para parodiar el Martín Fierro de José Hernández (el libro canónico de la gauchesca), el episodio borgeano por antonomasia: aquel en donde Cruz y Fierro se encuentran y dos órdenes de legalidad se enfrentan. Es este episodio, en efecto, el que mayores interpretaciones ha suscitado por parte de la crítica respecto de la actitud ambivalente de Borges frente a la cultura popular. En efecto, a lo largo de toda su obra, Borges regresará una y otra vez sobre la idea de "jugar a ser el otro" (según deja anotado en su "Anotación al 23 de agosto de 1944") encarnada en la "Historia del guerrero y la cautiva" en la doble pareja del bárbaro que abraza la causa de Ravena y la figura de la mujer europea que opta por la barbarie y el desierto. Es el mismo pasaje que atribuye también a este momento del Martín Fierro. Cruz, un policía, opta por defender a Fierro y ambos huyen al desierto. También sobre este momento Fontanarrosa tendrá su propia inversión que realizar. Porque así como Borges jugará a "ser el otro" a lo largo de su extensa obra; Fontanarrosa demostrará que ese otro puede también jugar, con sus propias reglas, el juego del primero. Es por eso mismo que Inodoro Pereyra decidirá no marcharse al desierto y "ser original", reescribiendo una vez más la escena gauchesca.

Creo que lo que Fontanarrosa nos está diciendo, en el lenguaje de la historieta, del humor y de la literatura, es que ese gran humorista que fue Fontanarrosa no desdeña en absoluto a ese otro gran humorista que fue Jorge Luis Borges. Fue en parte gracias al humor que Borges asimiló y reescribió la literatura y la cultura de Occidente (el particular occidente de Borges, sitiado y acosado por esas culturas "otras" que lo integraban). Y es justamente en el cuento "El Aleph", transposición paródica de La Divina Comedia, que ello se hace más evidente. Me parece que es esa la verdad sobre "El Aleph" que el relato nos viene a contar. Y es 
también a través del humor que Fontanarrosa recupera el gesto de Borges para la cultura popular y la historieta, reescribiendo también su literatura.

No es extraño, por lo tanto, que Borges se nos aparezca como El Monje, el inquietante demiurgo de La Balada del Mar Salado de Hugo Pratt. Desde las sombras de la isla La Escondida, El Monje conduce las acciones del resto de los personajes, de modo que al Corto, a Rasputín y a todos los demás, les resulta imposible prescindir de él. Sólo pueden hablar de él, contra él o a su favor; todo el tiempo buscan escapar de sus líneas de influencia, para volver a caer en sus redes, una y otra vez. Como El Monje en la historia de Pratt, lo que aparece escondido en la obra de Fontanarrosa, es esa presencia invisible y subterránea del padre Borges, no ya para todo lo que implica la literatura argentina, sino para aquello que es comúnmente percibido como un sector de esa literatura pero que la excede por mucho: el terreno de la creación fantástica.

Habrá que volver a preguntarse, entonces, hacia el final, quién o qué era Fontanarrosa.

\begin{abstract}
Al respecto propongo un tema de conversación, de una conversación sobre las formas del recuerdo, cuando se habla de narradores que nos llegan a través del papel impreso. Opino que cuando se recuerda a un escritor (digo: sobre todo si se trataba de un cuentista o novelista), se habla de sus temas y de sus ideas (o de las que se le atribuyeron), y de la emoción con que seguimos el desarrollo y los finales de sus relatos; cuando, en cambio, el recordado es un historietista, se habla de sus personajes, de sus mundos visuales o de sus gags, según su obra sea seria o cómica; de momentos de sus aventuras, de sus frases, de sus modos de decir... (Steimberg 2007)
\end{abstract}

¿Y de un humorista? ¿Qué es lo que se dice de ellos? Se recuerdan sin duda sus pensamientos, su particular modo de decir las cosas, se los anhela en lo que podrían extraer del presente para lo que fue su momento pasado. Se extraña la risa, no la de ellos, sino la nuestra. "Yo no digo que Fontanarrosa no haya sido escritor, pero creo que en los homenajes primó demasiado una cierta jerarquía de los lenguajes" -sigue Steimberg- y no podríamos estar más de acuerdo. Para nosotros, Fontanarrosa, sin dejar de ser un escritor, operaba, ante todo, como un humorista y es desde ese territorio, que sabía dominar a la perfección, desde el cual produjo algunas de sus más extraordinarias obras; obras que pertenecen al campo de la historieta y al de la literatura, pero por sobre todo, al campo del humorismo argentino.

\title{
OBRAS CITADAS
}

AA.VV. (1972, 1973, 1974): Hortensia, n. ${ }^{\circ}$ 24-61, diciembre de 1972-octubre de 1974.

Alifano, Roberto (1996): El humor de Borges. Montevideo, Ediciones de la Urraca.

Almeida, Iván, y Parodi, Cristina (ed.) (2001): "Dossier: Borges y el humor", Variaciones Borges, n. ${ }^{\circ}$ 12, pp. 5-121.

Abraham, Carlos (2005): Borges y la ciencia ficción. Buenos Aires, Quadrata. 
Adur Nobile, Lucas (2012): "Borges al cuadrado (o de cómo un grupo de superhéroes impidió que el mundo se convirtiera en Tlön)", Variaciones Borges, n. ${ }^{\circ} 33$, pp. 149169.

Aguilar, Gonzalo (2000): "Rodolfo Walsh: escritura y Estado". En: Jorge Lafforgue (ed.): Textos de y sobre Rodolfo Walsh. Alianza, Buenos Aires, pp. 61-72.

Borges, Jorge Luis (1989): Obras completas. Vol. 1. Buenos Aires, Emecé.

- (1989): Obras completas. Vol. 2. Buenos Aires, Emecé.

Bourdieu, Pierre (2002): Campo de poder, campo intelectual. Buenos Aires, Editorial Montressor.

Braceli, Rodolfo (1992): Fontanarrosa, Entregate. $Y$ vos también Boogie. $Y$ vos también Inodoro. Buenos Aires, Ediciones de la Flor.

Cédola, Estela (1999): Cómo el cine leyó a Borges. Buenos Aires, Edicial.

Cozarinsky, Edgardo (1981): Borges en/y/sobre cine. Madrid, Fundamentos.

Even-Zohar, Itamar (1999): Teoría de los Polisistemas. Madrid, Arco Libros.

(1990): Polysystem Studies. Durkham, Duke University Press.

Fernández Vega, José (1996): "Una campaña estética. Borges y la narrativa policial", Variaciones Borges, n. ${ }^{\circ}$ 1, pp. 27-66.

Fontanarrosa, Roberto (2005): El rey de la milonga. Buenos Aires, Ediciones de la Flor.

— (1998): 20 años con Inodoro Pereyra. Buenos Aires, Ediciones De la Flor.

— (1975): "Pabis, Gurus, Laxos \& Praxis", Satiricón, n. ${ }^{\circ} 23$, diciembre. (1974): "Hombre de la casa rosada", Satiricón, n. 19, junio.

García, Victoria (2012): "Caso Satanowsky de Rodolfo Walsh: repensando la cuestión del género", Recial. Revista del Ciffyh Área de Letras, Córdoba, vol. 3, n. ${ }^{\circ} 3$.

Gociol, Judith, y Naranjo, Marina (2008): 100\% negro Fontanarrosa. Buenos Aires, Fundación OSDE.

Gociol, Judith, y Rosemberg, Diego (2000): La Historieta Argentina Una Historia. Buenos Aires, Ediciones de la Flor.

Horkheimer, Max, y Adorno, Theodor (1994): Dialéctica de la llustración: fragmentos filosóficos. Madrid, Trotta.

Huyssen, Andreas (2006): Después de la gran división [1986]. Buenos Aires, Adriana Hidalgo. Jitrik, Noé (1971): "El tema del canto en el Martín Fierro de José Hernández". En: El fuego de la especie. Buenos Aires, Siglo xxı, pp. 13-46.

Lafforgue, Martín Ernesto (comp.) (1999): Antiborges. Buenos Aires, Javier Vergara Editor.

Lambert, José (2006): Functional Approaches to Culture and Translation. Amsterdam, John Benjamins Publishing Company.

Lamborghini, Leónidas (2008): Risa y tragedia en los poetas gauchescos. Buenos Aires, Emecé.

— (2003): "El gauchesco como arte bufo". En: Noé Jitrik (ed.): Historia crítica de la literatura argentina. Vol. 2. La lucha de los lenguajes. Buenos Aires, Emecé.

Link, Daniel (2003): "La escena de Fontanarrosa". En: Radar Libros. Suplemento de Página/12, 20 de abril. Disponible en <http://www.pagina12.com.ar/diario/suplementos/ libros/subnotas/539-81-2003-04-23.html>.

Louis, Annick (1997): Jorge Luis Borges: oeuvre et manoeuvres. París, L'Harmattan.

Maingueneau, Dominique (2010): "Campo discursivo". En: 12 conceitos para a análise do discurso. San Pablo, Parábola. 
- (2008): Gênese dos discursos. San Pablo, Parábola.

- (2005): O discurso literario. San Pablo, Contexto.

Martín, Marina (2004): "Humor y parodia en Borges: versiones de lo inverosímil", Variaciones Borges, n. ${ }^{\circ}$ 18, pp. 43-61.

Mazzocchi, Mirta Paula (1991): "Inodoro Pereyra y los chistes de gauchos". En: Ciudad/ Campo (en las Artes en Argentina y Latinoamerica), III Jornadas de Teoría e Historia de las Artes (C.A.I.A.).

Muñoz, Blanca (2000): Theodor W. Adorno: teoría crítica y cultura de masas. Madrid, Fundamentos.

- (1995): Teoría de la pseudocultura: estudios de sociología de la cultura y de la comunicación de masas. Madrid, Fundamentos.

Oesterheld, Hector G., y Breccia, Alberto (1982): El Eternauta. Buenos Aires, Ediciones de la Urraca.

Oubiña, David (2007): "El espectador corto de vista: Borges y el cine", Variaciones Borges, n. ${ }^{\circ} 24$, pp. $133-52$.

Palacios, Cristian (2014): Humor y Política. La dimensión ideológica del humor en la obra de Roberto Fontanarrosa. Tesis doctoral inédita. Universidad de Buenos Aires.

- (2013): "El lugar del payaso: la construcción de un ethos irrisorio en la obra historietística de Fontanarrosa". En: Actas de las /l Jornadas de Jóvenes Lingüistas. Buenos Aires, Facultad de Filosofía y Letras de la Universidad de Buenos Aires.

- (2012): "Algún lugar de Dharam. Boogie frente a los medios masivos de comunicación". En: Actas del I/ Congreso Internacional sobre Historieta y Humor Gráfico "Viñetas Serias". Buenos Aires, Biblioteca Nacional.

Parodi, Cristina (1999): "Borges y la subversión del modelo policial". En: Borges: desesperaciones aparentes y consuelos secretos. México, El Colegio de México.

Pereira, Priscila (2011): Entre a épica e a paródia. A (des) mistificação do gaucho nos quadrinhos de Inodoro Pereyra, el renegau. Campinas, Universidade Estadual de Campinas.

Possenti, Sírio (2010): Humor, língua e discurso. San Pablo, Contexto.

Pratt, Hugo (2003): Corto Maltés. Buenos Aires, Biblioteca Clarín de la Historieta.

Costa, René de (1999): El humor en Borges. Madrid, Cátedra.

Schvartzman, Julio (2013): Letras gauchas. Buenos Aires, Eterna Cadencia.

Speranza, Graciela (2006): "El arte narrativo y el cine". En: Fuera de campo. Literatura y arte argentino después de Duchamp. Barcelona, Anagrama.

Steimberg, Oscar (2013): Semióticas. Las semióticas de los géneros, de los estilos, de la transposición. Buenos Aires, Eterna Cadencia.

- (2007): "Ahora que pasaron: sobre los homenajes a Fontanarrosa", Crítica. Revista electrónica del área de Crítica de Arte del IUNA, año 2, n. ${ }^{\circ} 2$, octubre.

Swingewood, Alan (1977): The Myth of Mass Culture. Londres, Macmillan Press.

Turbio, María Luján (2006): "El Aleph" y la hiperrealidad mística", Espéculo. Revista de estudios literarios, n. ${ }^{\circ}$ 32. Disponible en <https://pendientedemigracion.ucm.es/ info/especulo/numero32/alephmi.html>. 